\title{
Expression patterns of three $\alpha$-expansin isoforms in Coffea arabica during fruit development
}

\author{
I. G. F. Budzinski ${ }^{1,2}$, T. B. Santos ${ }^{1,2}$, T. Sera ${ }^{1}$, D. Pot ${ }^{3}$, L. G. E. Vieira ${ }^{1}$ \& L. F. P. Pereira ${ }^{1,4}$ \\ 1 Instituto Agronômico do Paraná, IAPAR, LBI-AMG, Londrina, Paraná, Brazil \\ 2 Universidade Estadual de Londrina, UEL, CEP Londrina, Paraná, Brazil \\ 3 CIRAD UMR DAP, Montpellier, France \\ 4 EMBRAPA Café, Londrina, Paraná, Brazil
}

\section{Keywords}

Coffee; expansin isoforms; fruit ripening; grain quality; perisperm.

\section{Correspondence}

L. F. P. Pereira, IAPAR/EMBRAPA Café; Cx 481, 86047-902, Londrina, Paraná, Brazil. E-mail: Ipereira@iapar.br

\section{Editor}

S. Wick

Received: 8 February 2010; Accepted: 28 July 2010

doi:10.1111/j.1438-8677.2010.00400.x

\begin{abstract}
As a first step towards understanding the physiological role and regulation of the expansin gene (EXP) family in Coffea arabica fruits during growth and maturation, we identified 11 expansin genes, nine belonging to the $\alpha$-expansin family (EXPA), one EXLA and one EXLB, through in silico analysis of expressed sequence tags (ESTs). Within the $\alpha$-expansin family, three isoforms were selected for detailed examination based on their high expression in coffee fruits or because they were specifically induced during different fruit developmental stages, according to the EST information. The expression patterns were analysed in different fruit tissues (perisperm, endosperm and pericarp) of $C$. arabica $\mathrm{cv}$. IAPAR-59 and C. arabica cv. IAPAR-59 Graúdo, the latter being a closely related cultivar with a larger fruit size. Accumulation of CaEXPA1 and CaEXPA3 transcripts was high in the perisperm (tissue responsible for coffee bean size) and in the early stages of pericarp development. Transcripts of CaEXPA2 were detected only in the pericarp during the later stages of fruit maturation and ripening. There was no detectable transcription of the three EXPs analysed in the endosperm. The observed differences in mRNA expression levels of CaEXPA1 and CaEXP3 in the perisperm of IAPAR-59 and IAPAR-59 Graúdo suggest the participation of these two isoforms in the regulation of grain size.
\end{abstract}

\section{INTRODUCTION}

Coffee is one of the most valuable traded commodities in the world, being cultivated in more than 60 countries. Commercially, coffee production relies only on two species, Coffea arabica L. and C. canephora Pierre ex Froehner, which represent about $70 \%$ and $30 \%$ of the total coffee market, respectively (Vieira et al. 2006). Coffee quality has been associated with the ripening stages of fruits during harvest time, among other factors. In coffee growing regions with good rainfall distribution, flowering can occur over a long period. In this case, fruit growth is asynchronous during development, resulting in the presence of fruits at different ripening stages in the same plant. The presence of green fruits and over-ripe fruits in the same batch of grains changes the acidity, bitterness and, consequently, the quality of the beverage (Pereira et al. 2005). Besides the biochemical composition, coffee cup quality is also directly related to the structural features of the mature grain. The coffee grain size and its uniformity are important attributes for quality as well as for market price, since these characteristics are associated with higher prices according to international standards of classification.

In $C$. arabica, the time from anthesis to full ripening of fruits is 6-8 months (De Castro \& Marraccini 2006). The C. arabica fruit is mainly composed of pericarp and perisperm tissues at the early stages of development (from pollination up to 90 days after flowering - DAF). The perisperm undergoes intense cell division and expansion during these early stages of fruit development. This tissue is considered to be responsible for defining the final coffee grain size (De Castro \& Marraccini 2006). During later stages of fruit development, the perisperm gradually disappears and is progressively replaced by the endosperm (true seed). Initially present in a 'liquid' state, the endosperm hardens as it ripens during the maturation phase as a result of the accumulation of storage proteins, sucrose and complex polysaccharides that represent the main seed reserves. The last step of maturation is characterised by dehydration of the endosperm and colour change of the pericarp (Eira et al. 2006). At this late ripening stage, the fruit starts climacteric development, with an ethylene burst and intense biochemical activity of cell wall loosening enzymes (Pereira et al. 2005). During fruit growth, cell enlargement is tightly linked to one or more loosening processes that modify the linkage of cellulose microfibrils to one another and to the cell wall matrix (Yong et al. 2007). Different proteins and enzymes acts as agents of cell wall loosening, e.g., expansins, xyloglucan endotransglycolases/hydrolases and endo-(1,4)- $\beta$-d-glucanases (for a review see Cosgrove 2005).

Expansins are plant cell wall loosening proteins that were first described in expanding/growing tissues as proteins that induce cell wall extension and stress relaxation at acidic $\mathrm{pH}$ (McQueen-Mason et al. 1992). It has been proposed that 
expansins bind to the interface between microfibrils and polysaccharides and facilitate cell wall extension by catalysing the disruption of hydrogen bonds at the cellulose-hemicellulose interface, thereby facilitating turgor-driven slippage between microfibrils and other components of the cell wall (McQueen-Mason \& Cosgrove 1995; Cosgrove 2000). These proteins play important roles in a range of developmental processes, including fruit softening (Brummell et al. 1999), pollination (Cosgrove et al. 1997), meristem dynamics (Fleming et al. 1997), root development (Zhang \& Hasenstein 2000), cell enlargement, seed germination, abscission, stress responses and parasitism (reviewed by Choi et al. 2006). Expansin action during fruit development and ripening has been investigated in tomato (Rose et al. 1997; Brummell et al. 1999; Powell et al. 2003), peach (Obenland et al. 2003), fig (Omondi et al. 2004), mango (Sane et al. 2005) strawberry (Civello et al. 1999; Dotto et al. 2006), banana (Trivedi \& Nath 2004; Asha et al. 2007) and grape (Ishimaru et al. 2006). Expansins are encoded by a multigene family and, based on sequence similarity, these proteins can be divided into four subfamilies, namely $\alpha$-expansin (EXPA), $\beta$-expansin (EXPB), expansin-like A (EXLA) and expansin-like B (EXLB). $\alpha$-Expansin and $\beta$-expansin have been demonstrated experimentally to cause cell wall loosening (Cosgrove et al. 1997; Li et al. 2003), whereas expansin-like A and expansin-like B are known only from their gene sequences (Sampedro \& Cosgrove 2005). Expansins have a signal peptide containing about 20 amino acids at their N-terminus, which directs the polypeptide into the endoplasmic reticulum/Golgi secretory pathway (Lin et al. 2005). EXPAs and EXPBs have conserved cysteine residues in the $\mathrm{N}$-terminal putative catalytic domain, a histidine-phenylalanine-aspartate (HPD) motif in the centre region and conserved tryptophan residues in the C-terminal putative cellulose binding domain (Choi et al. 2006).

Following previous studies on characterisation of genes and biochemical changes occurring during coffee fruit development and maturation (Geromel et al. 2006, 2008; Pereira et al. 2005; Salmona et al. 2008), the present work describes the transcription profile of three $\alpha$-expansin isoforms that are related to changes in grain size and to the final process of ripening of $C$. arabica fruits.

\section{MATERIAL AND METHODS}

\section{Search for C. arabica expansin sequences}

Expressed sequence tags (ESTs) coding for expansins were selected from the database of the Brazilian Coffee Genome Project (http://www.lge.ibi.unicamp.br/cafe) through a keyword search. This EST database contains 130,792 ESTs of C. arabica, 12,381 ESTs of C. canephora and 10,566 ESTs of C. racemosa, distributed into 37 cDNA libraries sequenced from the 5' end (Vieira et al. 2006). After local BLAST searches, all the singlets and contigs of candidate expansin unigenes were re-assembled using the software Sequencher 4.2 (Gene Codes Corporation, Ann Arbor, MI, USA). The unigenes thus generated were compared with those in the NCBI database using the BLASTX program (http:// www.ncbi.nlm.nih.gov/BLAST; Altschul et al. 1990). The open-reading frame (ORF) of each unigene was predicted using the ORF Finder program (NCBI). ScanProsite (http:// www.expasy.org) was used to verify the two domains specific for mature expansin proteins and to indicate the N-glycosylation linkage site. The pollen allergen domain was verified for each isoform using BLASTP. Signal peptide predictions were performed using SignalP version 3.0 (http://www.cbs.dtu.dk/ services/SignalP). Using the deduced amino acid sequences, full-length proteins were aligned using CLUSTALW. The phylogenetic tree was constructed with MEGA - Molecular Evolutionary Genetics Analysis, version 3.1, software. The aligned sequences were used as the basis for construction of a comprehensive tree to verify similarity within the coffee expansin sequences and also to classify each expansin into a gene family (EXPA, EXPB, EXP-like-A and EXP-Like-B) using Arabidopsis thaliana (At), Medicago trunculata (medi), Gossypium hirsutum (cot), Solanum lycopersicum (toma) and Lactuca sativa (let), as recommended at the website http://www.bio. psu.edu/expansins/naming.htm: AtEXPA1 (NM_105622), AtEXPA2 (U30481.3), AtEXPA4 (NM_129526), AtEXPA6 (NM_ 128454), AtEXPA7 (NM_101127), AtEXPA8 (NM_129623), AtEXPA10 (NM_102440), AtEXPB1 (NM_127640), AtEXPB2 (NM_105241), AtEXPB3 (NM_118965), AtEXLA1 (NM_1144 66), AtEXLA2 (NM_120002), AtEXLA3 (NM_001035738), AtEXLB1 (NM_117807), medi(TC88001), cot1(CD809349), $\cot 2$ (TC21359), toma (TC118460) and let(TC982). We also include sequences from Pyrus communis (Pc), Malus domestica (Md) and Musa acuminata (Ma): PcExp1 (BAC67188.1), PcExp2 (BAC67189.1), PcExp3 (BAC67190.1), PcExp4 (BAC67191.1), PcExp5 (BAC67192.1), PcExp6 (BAC67192.1), PcExp7 (BAC67194.1), MdEXPA3 (BAD00013.1), MaEXP1 (AAM08930.1), MaEXP2 (AAN16378.2), MaEXP3 (ABM664 30.1), MaEXP4 (ABN09939.1) and MaEXP5 (ABN09940.1).

The phylogenetic trees were inferred from a neighbor-joining tree using the Kimura two-parameter model. Bootstrap analysis was carried out (1000 trials) to assess support for individual nodes.

\section{Plant material}

Fruits and other plant tissues (roots, plagiotropic shoots, leaves, flower buds and flowers) were harvested from C. arabica cv. IAPAR-59 plants, cultivated under field conditions at the experimental station of the Agronomic Institute of Paraná (Londrina, Brazil). Fruits were also collected from C. arabica cv. IAPAR-59 Graúdo, a closely related genotype having a larger fruit size (see Fig. S1 in the Supporting information section).

Fruits were collected monthly after flowering (end of September 2006) until complete maturation (end of April 2007). At the final stages of maturation (March and April), fruits were also classified based on pericarp colour (Table 1). After harvesting, all samples were immediately frozen in liquid nitrogen and stored at $-80{ }^{\circ} \mathrm{C}$ until RNA extraction. To observe spatial and temporal differences in expansin transcriptional activity, fruit tissues were dissected (pericarp, perisperm and endosperm) and used independently for RNA extraction.

\section{Genomic DNA and RNA extraction}

Genomic DNA was extracted from young leaves of C. arabica cv. IAPAR-59 and cv. IAPAR-59 Graúdo with the cetyltrimethylammonium bromide (CTAB) method (Doyle \& Doyle 
Table 1. Coffea arabica fruits grouped according to month and pericarp colour for molecular analysis.

\begin{tabular}{llll}
\hline & $\begin{array}{l}\text { days after } \\
\text { flowering } \\
\text { (DAF) }\end{array}$ & $\begin{array}{l}\text { pericarp } \\
\text { colour }\end{array}$ & developmental stage \\
\hline October/2006 & 30 & green & initial expansion \\
November/2006 & 60 & green & (perisperm \\
December/2006 & 90 & green & development) \\
January/2007 & 120 & green & endosperm formation \\
February/2007 & 150 & green & (grain filling) \\
March/2007 & 180 & green-red & fruit ripening \\
April/2007 & 210 & yellow-cherry & \\
\hline
\end{tabular}

a Only green fruits were available from C. arabica cv. IAPAR 59 in March, whereas for C. arabica cv. IAPAR-59 Graúdo there were fruits with different pericarp colours.

1987). To analyse the expansin transcription patterns, total RNA from different plant parts and fruit tissues (pericarp, perisperm and endosperm) at different stages of development were extracted as described by Geromel et al. (2006, 2008). Total RNA quantification was performed using a Qubit fluorometer (Invitrogen, Carlsbad, CA, USA).

\section{Cloning and sequencing of coffee $\alpha$-expansin isoforms}

First-strand cDNA was synthesised from total RNA $(1 \mu \mathrm{g})$ using the ThermoScript ${ }^{\text {TM }}$ RT-PCR system (Invitrogen) according to the manufacturer's instructions. Based on sequences of the three selected $\alpha$-expansin contigs, specific primers were designed using the software Primer Designer version 2.0: CaEXPA1 sense 5'-TTC CGA TGG CGT TCT CCT CC $-3^{\prime}$ and antisense 5'-GTC GTT AGT GAT AGG CAG T-3'; CaEXPA2 sense 5'-GAG CAA GTG ACC GTC GCT CTT CCA CT- $3^{\prime}$ and antisense $5^{\prime}$-CTA TGA ATC ATG GTT CGA C-3'; CaEXPA3 sense 5'-CGA GCG TAT TGC ACC TCC; antisense 5'-CAC GTT GCG GGG CAT ACA AT$\left.3^{\prime}\right)$. PCR was performed under the following conditions: initial denaturation at $94{ }^{\circ} \mathrm{C}$ for $5 \mathrm{~min}$, followed by 40 cycles of $94{ }^{\circ} \mathrm{C}$ for $1 \mathrm{~min}, 60^{\circ} \mathrm{C}$ for $45 \mathrm{~s}, 72^{\circ} \mathrm{C}$ for $1 \mathrm{~min}$ and a final extension step of $72{ }^{\circ} \mathrm{C}$ for $5 \mathrm{~min}$. Reaction products were analysed on a $1 \%$ agarose gel. The amplified DNA fragment obtained for each coffee expansin isoform was ligated in pTOPO2.1 (Invitrogen) and amplified in E. coli TOP10 cells. Plasmid DNA was prepared by alkaline lysis, column-purified (Qiagen, Chatsworth, CA, USA), and both strands of the cloned cDNA fragments were sequenced in a MegaBACE 1000 DNA Analysis System (GE Life Science, Pittsburg, PA, USA).

The nucleotide sequences of the full-length CaEXPA1, 2 and 3 cDNAs described here have been submitted to GenBank and the assigned accession numbers are GQ434001, GQ434002 and GQ434003, respectively.

\section{Northern and Southern blot analysis}

Total RNA $(15 \mu \mathrm{g})$ was denatured in $12.55 \mathrm{~m}$ formamide, $2.2 \mathrm{~m}$ formaldehyde and $20 \mathrm{~mm} 3$-( $\mathrm{N}$-morpholino)-propanesulphonic acid (MOPS) buffer, pH 7.0 (also containing $5 \mathrm{~mm}$ Na-acetate and $0.1 \mathrm{~mm}$ EDTA) at $65^{\circ} \mathrm{C}$ for $15 \mathrm{~min}$ and fractionated on a $1.2 \%(\mathrm{w} / \mathrm{v})$ agarose gel containing $2.2 \mathrm{M}$ formaldehyde in 10× MOPS buffer. The RNA was transferred to nylon membranes by capillarity according to Sambrook et al. (1989). Membranes were pre-hybridised at $37^{\circ} \mathrm{C}$ for $2 \mathrm{~h}$ using the buffer UltraHyb ${ }^{\circledR}$ (Ambion, Austin, TX, USA). The cDNAs of each $\alpha$-expansin were used as a template for probe synthesis. The probes were checked for specificity using a dot blot containing the nucleic acids of the three EXPA isoforms. Probes were labelled with $\left[\alpha-\mathrm{P}^{32}\right]$-dCTP using random priming, and the membranes were hybridised at $37^{\circ} \mathrm{C}$ overnight in the same buffer. After hybridisation, membranes were washed twice for $10 \mathrm{~min}$ with $1 \times$ SSC:0.1\% SDS solution follow by washing twice for $10 \mathrm{~min} 1 \times$ SSC:0.1\% SDS. The membranes were exposed to film BAS-IP MS 2340. Images were captured using a fluorescence image analyser, FLA 3000 series (Fuji Photo Film CO, Ltd. Tokyo, Japan). For Southern blot analysis, $10 \mu \mathrm{g}$ DNA were digested with the restriction endonuclease HindIII (except for CaEXP1 where DraI was used), resolved on $0.8 \%$ (w/v) agarose gels, transferred to nylon membranes and hybridised with the same probes as described above.

\section{RESULTS}

Coffee expansin identification and phylogenetic analysis

Data mining of the Brazilian Coffee Genome Project database (http://www.lge.ibi.unicamp.br/cafe/) yielded 11 candidate unigenes that corresponded to annotated expansin sequences. To confirm that all selected unigene clusters share similarities with expansins from others organisms, each consensus sequence was analysed at NCBI using BLASTX. DNA sequence analysis of the selected full-length cDNAs indicated that they were essentially unique sequences representing different expansin genes.

Based on analysis with the SignalP program, it was found that each coffee expansin protein had a cleavable signal peptide at the $\mathrm{N}$-terminus. The length of this peptide varied, ranging from 18 to 31 residues. For all unigenes, there were two characteristic domains of expansin proteins: a cysteinerich region (first domain) and a tryptophan-rich C-terminal portion (second domain). To classify the 11 coffee expansins within the four expansin families presently known ( $\alpha$-EXP, $\beta$-EXP, EXLA and EXLB), a phylogenetic tree was generated from the alignment of the deduced amino acid sequences of the putative coffee expansins and expansins from A. thaliana, O. sativa, S. lycopersicum, M. truncatula and L. sativa, as recommended (http://www.bio.psu.edu/expansins/naming.htm; Fig. 1) Among the nine C. arabica $\alpha$-expansins identified from the phylogenetic tree, three were selected (CaEXPA1, CaEXPA2 and CaEXPA3) for detailed examination based on the number of reads in coffee fruit cDNA libraries or their specific induction in fruits during different developmental stages.

\section{Characteristics of CaEXPA1, CaEXPA2 and CaEXPA3 coffee $\alpha$-expansins}

The predicted proteins of CaEXPA1 (257 amino acids), CaEXPA2 (258 amino acids) and CaEXPA3 (254 amino acids) provided the main features of this expansin subfamily, such as conserved cysteine $(\mathrm{C})$ residues in the N-terminal region, 


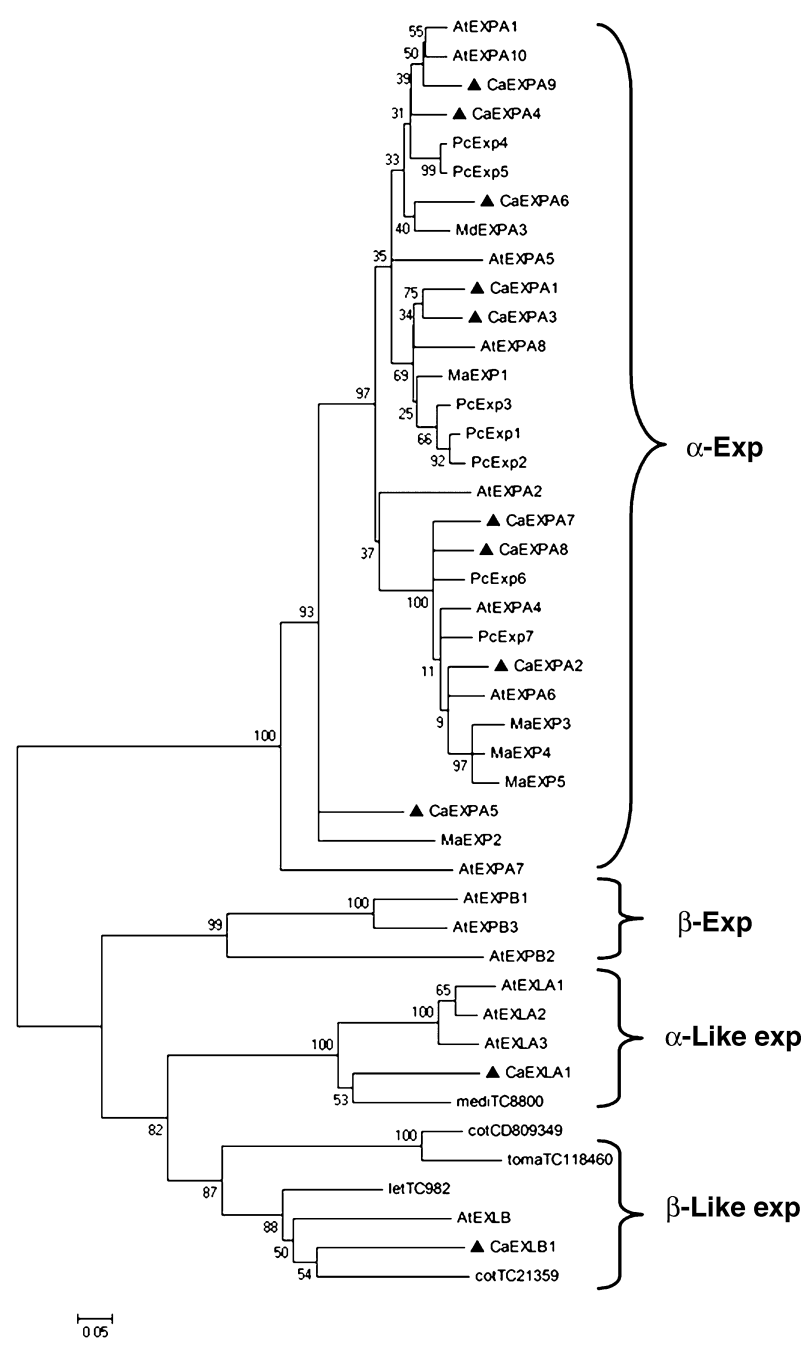

Fig. 1. Phylogenetic comparison of expansin protein sequences. Using the deduced amino acid sequences, full-length proteins were aligned using CLUSTALW. The phylogenetic tree was constructed using Mega version 3.1 software. Black triangles indicate coffee expansins. The other sequences represent different expansin families ( $\alpha$-expansin, $\beta$-expansin, expansin-like A and expansin-like B).

an HPD domain (a catalytic site of the family 45-glycosyl hydrolases) and conserved tryptophan (W) residues at the C-terminal portion (Fig. 2). However, some variations specific to coffee expansins were also observed in the residues. For example, CaEXPA1 had two $\mathrm{W}$ residues in the first domain (N-terminal) while CaEXPA2 and CaEXPA3 had three. In the second domain (C-terminal), CaEXPA2 had five tryptophan residues while the other two isoforms had only four (Fig. 2).

\section{Southern blot analysis}

Southern blot analyses were carried out to determine the complexity of the three expansin genes in C. arabica cv. IAPAR-59 and cv. IAPAR-59 Graúdo (Fig. 3). Prior DNA blot analyses with different probes, under high stringency washing, revealed restriction fragments of different sizes for the three coffee expansins, indicating that the probes were gene-specific. Hybridisations with specific probes revealed two major bands for the three coffee $\alpha$-expansin isoforms. This indicates that CaEXPA1, CaEXPA2 and CaEXPA3 are present in two copies. Hybridisation patterns of CaEXPA1 and CaEXPA2 in genomic DNA from cv. IAPAR-59 and cv. IAPAR-59 Graúdo were similar (Fig. 3). However, hybridisation with the CaEX$P A 3$ probe yielded a difference in band size between the two cultivars (Fig. 3).

\section{Expression of EXPA genes during fruit development and ripening}

To examine the potential role of $\alpha$-expansins in coffee fruit development and ripening, the hybridisation patterns of entire fruits with probes for CaEXPA1, CaEXPA2 and CaEXPA3 were evaluated at different developmental stages. Total RNAs from entire fruits were isolated each month (30-210 DAF) from cv. IAPAR-59 and cv. IAPAR-59 Graúdo. Transcript expression patterns of $C a E X P A 1$ and $C a E X P A 3$ were similar during the early stages of fruit development and in the final steps of fruit ripening for cv. IAPAR-59 (Fig. 4). Increased transcripts of these two isoforms were present at $60 \mathrm{DAF}$, a period of rapid fruit expansion and perisperm development (tissue responsible for defining final coffee grain size). In the genotype cv. IAPAR-59 Graúdo, we also observed transcripts of CaEXPA1 and CaEXPA3 at 60 DAF (Fig. 4), however there was a higher accumulation of mRNA at 90 DAF, which may indicate that, in this genotype, fruit expansion and perisperm development had continued until 90 DAF.

Increased transcripts of CaEXPA1 and CaEXPA3 were also observed at the final stages of ripening: April (210 DAF) for IAPAR-59 and March for IAPAR-59 Graúdo. These results suggest the participation of both isoforms in the fruit development and ripening process. In contrast, isoform CaEXPA2 (Fig. 4) showed specific expression only during the latest stages of fruit ripening for both cultivars, at the time when the process of pericarp cell wall disassembly is initiated.

\section{Expression of EXPA genes in individual fruit tissues}

To examine differences in the transcription pattern of each isoform in different coffee fruit tissues, mRNA levels were evaluated individually for the pericarp (90-210 DAF), perisperm (90-150 DAF) and endosperm (90-210 DAF). For cv. IAPAR59, transcription of CaEXPA1 was observed in the pericarp from 90 DAF, reaching a maximum at 210 DAF stages: from yellow-red, light-red, red to cherry at 210 DAF; Fig. 5). In cv. IAPAR-59 Graúdo, increased expression of CaEXPA1 was already observed in the pericarp at $90 \mathrm{DAF}$, the final step of rapid fruit expansion. Expression of this isoform was also observed in the pericarp at 180 DAF as well as in the final steps of ripening (210 DAF, April - cherry fruit; Fig. 5).

CaEXPA3 showed the same transcription pattern as CaEXPA1, except for a smaller hybridisation signal in $\mathrm{cv}$. IAPAR-59 at 210 DAF - cherry stage. CaEXPA2 mRNA accumulation in the pericarp of IAPAR-59 and IAPAR-59 Graúdo coincided quite well with the pattern observed for the whole fruit (Fig. 4), with a hybridisation signal detected only during the ripening stages.

The perisperm tissue was already reduced to a thin membrane surrounding the endosperm at the beginning of fruit ripening (from 180 DAF onward), which hindered extraction 


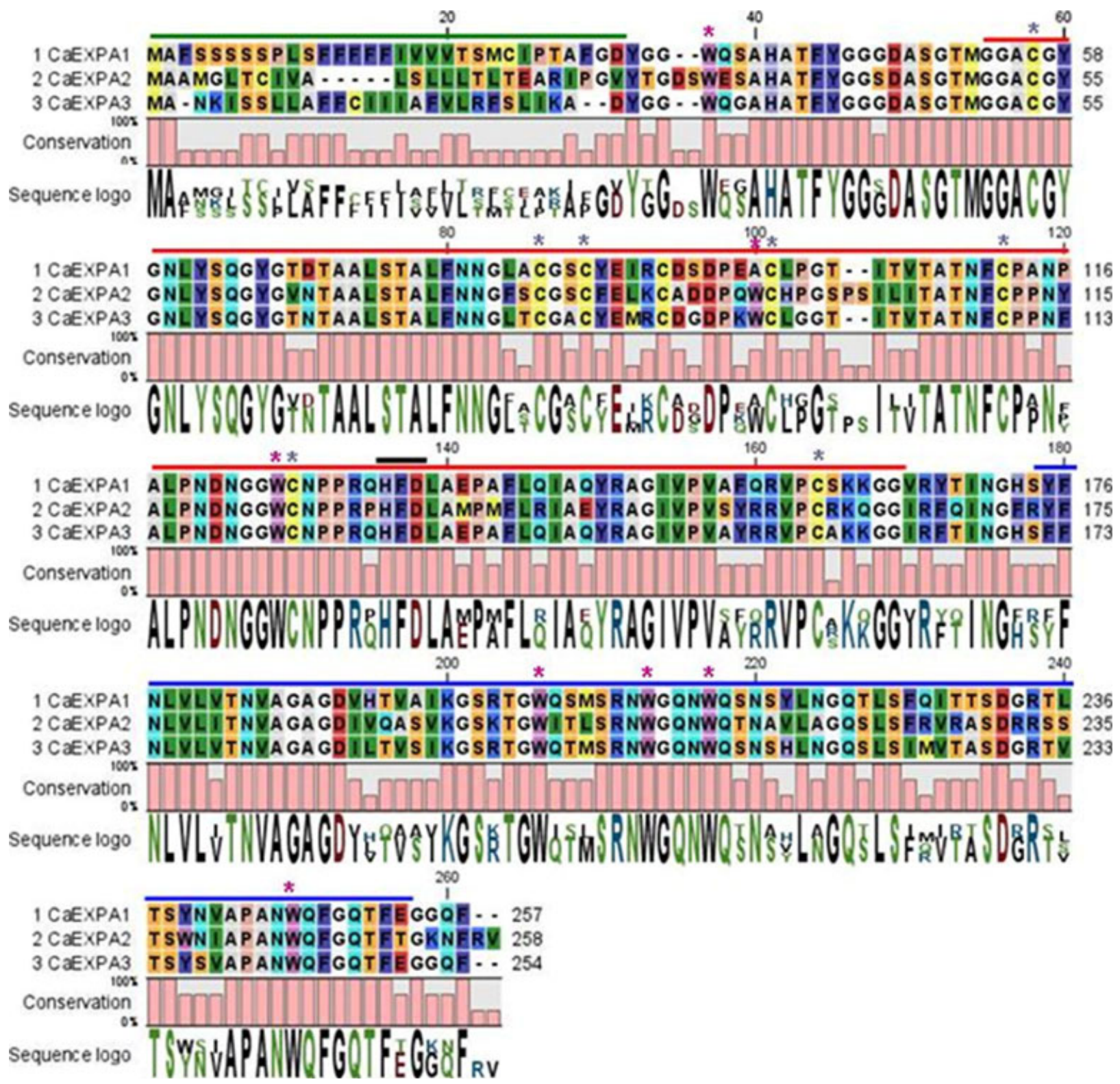

Fig. 2. Alignment of the deduced amino acid sequence of three coffee $\alpha$-expansins. Green bar indicates the signal peptide predicted by the SignalP program (http://www.cbs.dtu.dk/services/SignalP/). The potential putative catalytic domain (N-terminal) is indicated by a horizontal red bar and the putative cellulose binding domain (C-terminal) is indicated by a horizontal blue bar, both were predicted using ScanProsite. Purple asterisks $\left({ }^{*}\right)=$ conserved tryptophan (W) residues; grey asterisks = conserved cysteine (C) residues. Multiple alignment was done with the CLC Workbench software.

of RNA for Northern blot analysis. CaEXPA1 expression was observed in all perisperm tissues analysed from both cv. IAPAR-59 and cv. IAPAR-59 Graúdo, but at a much higher intensity at 90 DAF (Fig. 6). CaEXPA2 expression was not observed in the perisperm (data not shown). Weak CaEXPA3 transcriptional activity was observed in the perisperm of both cultivars only at 90 DAF (Fig. 6). No transcription was detected in the endosperm for any of the three EXPA isoforms tested (data not shown).

Expression of EXPA genes in non-fruit tissues

CaEXPA1, CaEXPA2 and CaEXPA3 mRNA accumulation was also investigated in roots, young and old branches, flower buds, flowers and leaves of C. arabica cv. IAPAR 59 (Fig. 7). Detection of CaEXPA1 and CaEXPA3 transcripts was strong in flower buds, which are tissues with a high level of cell division. Transcripts of CaEXPA1 were also observed at lower intensities in roots and young branches. CaEXPA2 mRNA levels were low in roots, young and old branches and barely detectable in flower buds.

\section{DISCUSSION}

Coffee fruits have unusual tissue organisation and development. In C. arabica, the perisperm constitutes the predominant tissue occupying the inner space (locule) of fruits until 90-100 DAF. This locule space is delimited by the endocarp, 


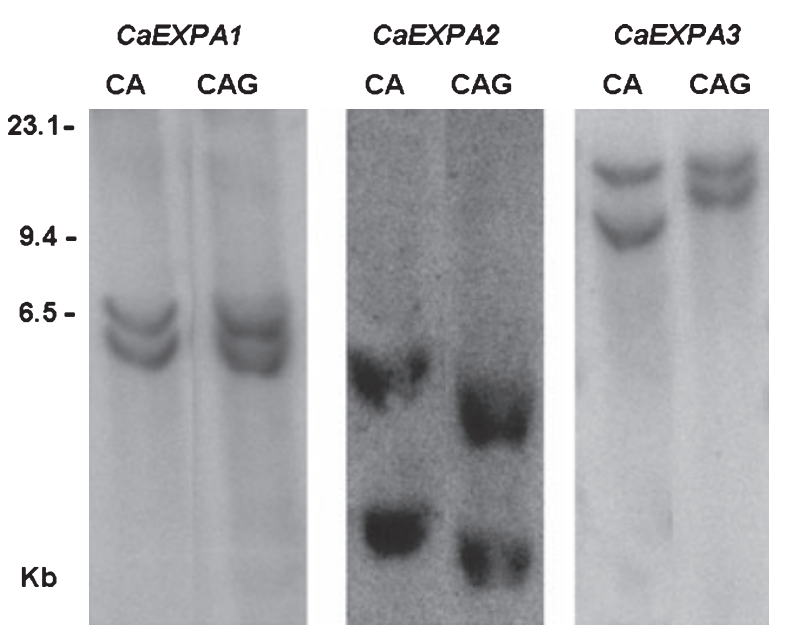

Fig. 3. DNA gel blot analysis. Genomic DNA from CV. IAPAR-59 and IAPAR-59 Graúdo were digested with the restriction enzymes Dral (CAEXPA1) or Hindlll (CaEXPA2 and CaEXPA3) and hybridised with probes from the cDNAs of each $\alpha$-expansin.

which is a hard and cellulose-rich tissue present from the early stages of fruit development (De Castro \& Marraccini 2006). With growth of the fruit, this space is rapidly occupied by the endosperm, while the perisperm (at this point referred to the silver skin) becomes a thin tissue reduced to few cell layers surrounding the endosperm (Geromel et al.
2006, 2008). Therefore, the space occupied by the perisperm determines the final grain size. Towards the end of coffee fruit maturation, when endosperm development is complete, the final process of ripening is initiated. Similar to other climacteric fruits, a burst of ethylene occurs, followed by an increase in size and change in colour of the pericarp (Pereira et al. 2005). The expansin gene family is involved in different steps of fruit development and there are several reports on their temporal and spatial gene activity (Rose et al. 1997; Hayama et al. 2006; Ishimaru et al. 2006; Asha et al. 2007). Given that expansins may have a relevant role in perisperm expansion and fruit maturation, the main objective of this study was to analyse the tissue specificity and temporal expression pattern of three $\alpha$-expansin isoforms during coffee fruit development.

Initially, we identified 11 C. arabica expansin clusters within the Brazilian Coffee Genome Project database. All the hypothetical proteins exhibit specific functional motifs and domains that are characteristic of the expansin family. Based on phylogenetic analysis, these clusters were classified into nine $\alpha$-expansins, one expansin-like A and one expansin-like B. In Arabidopsis, 36 expansin genes have been reported (26 $\alpha$-expansins, six $\beta$-expansins, three expansins-like $A$ and one expansin-like B), while 58 expansins have been identified in rice (34 $\alpha$-expansins, $19 \beta$-expansins, four expansin-like A and one expansin-like B) (Sampedro et al. 2005). The $\beta$-expansin family is more common in monocotyledons than in dicotyledons (Cosgrove 2000), which could explain the
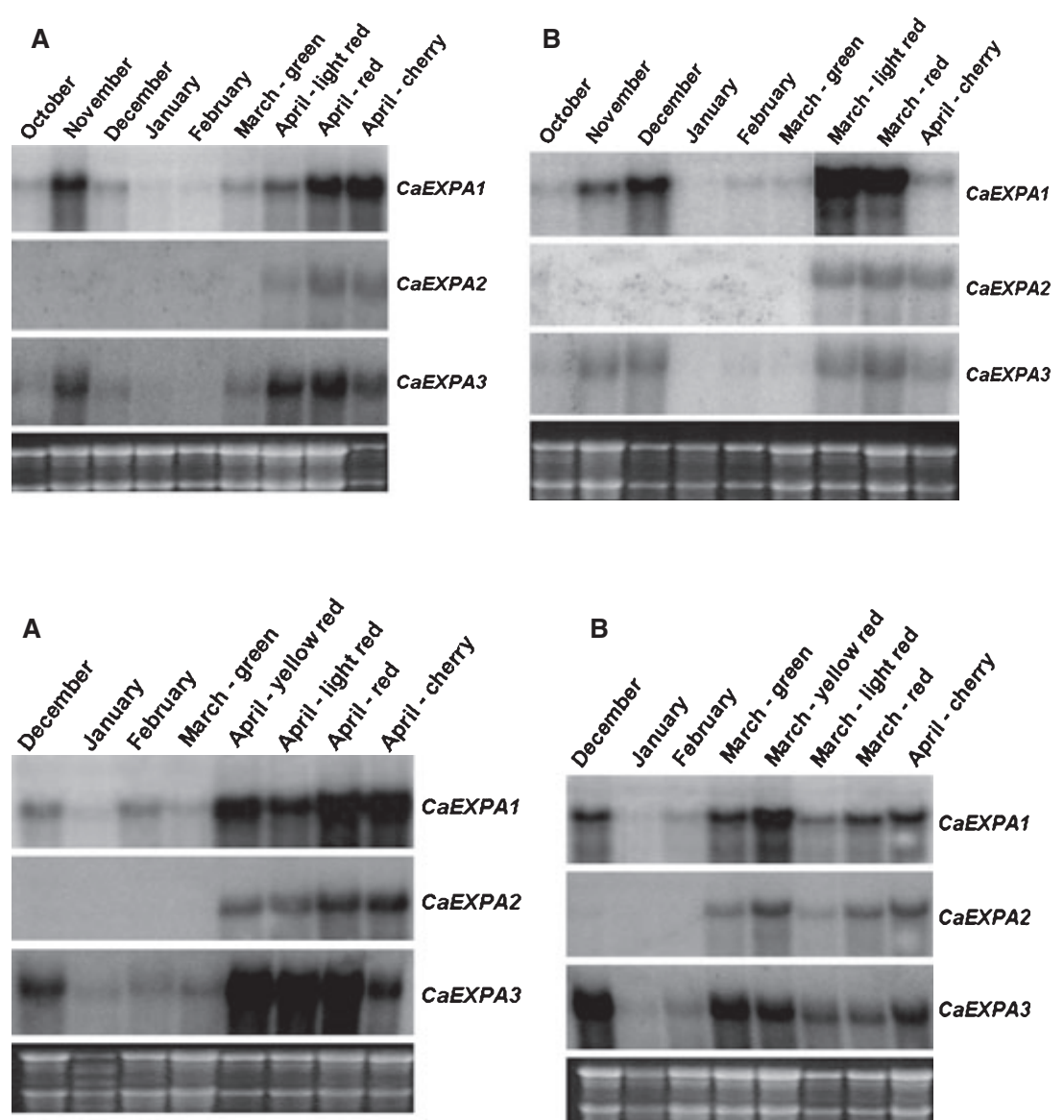

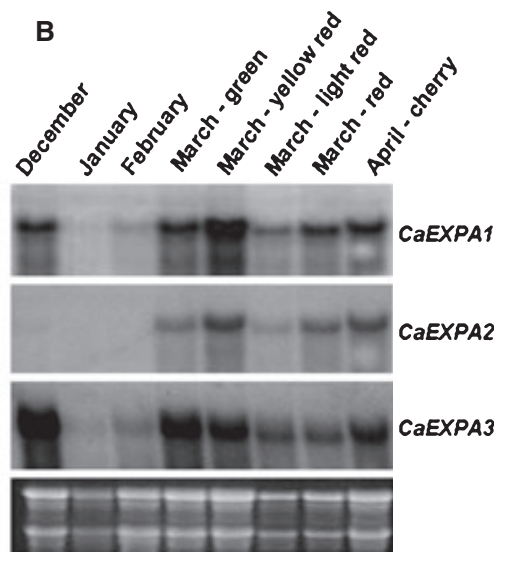

Fig. 4. Expression of CaEXPA1, CaEXPA2 and CAEXPA3 during coffee fruit development and ripening. Total RNA $(15 \mu \mathrm{g})$ was isolated from whole fruits of cV. IAPAR-59 (A) and cv. IAPAR-59 Graúdo (B). Fruits were collected each month after flowering: October (30 DAF), November (60 DAF), December (90 DAF), January (120 DAF), February (150 DAF), March (green, light-red, red, 180 DAF) and April (light-red, red and cherry, 210 DAF). Ethidium bromide-stained gel prior to blotting is shown below the blot as a loading control.
Fig. 5. Expression of CaEXPA1, CaEXPA2 and CaEXPA3 in the pericarp during coffee fruit development and ripening. Total RNA $(15 \mu \mathrm{g})$ was isolated from the pericarp of $c v$. IAPAR-59 (A) and cv. IAPAR59 Graúdo (B). Fruits were collected each month after flowering: December (90 DAF), January (120 DAF), February (150 DAF), March (green, yellow-red, light-red and red, $180 \mathrm{DAF}$ ) and April (light-red, red and cherry, 210 DAF). Ethidium bromide-stained gel prior to blotting is shown below the blot as a loading control. 
A
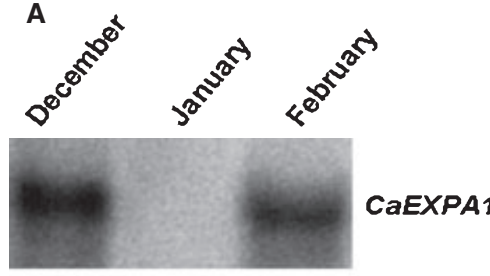

Fig. 6. Expression of CaEXPA1 and CaEXPA3 during coffee fruit development and ripening. Total RNA $(15 \mu \mathrm{g})$ was isolated from the perisperm of $\mathrm{cV}$. IAPAR-59 (A) and cv. IAPAR-59 Graúdo (B). Fruits were collected each month after flowering: December (90 DAF), January (120 DAF), February (150 DAF). Ethidium bromide-stained gel prior to blotting is shown below the blot as a loading control.

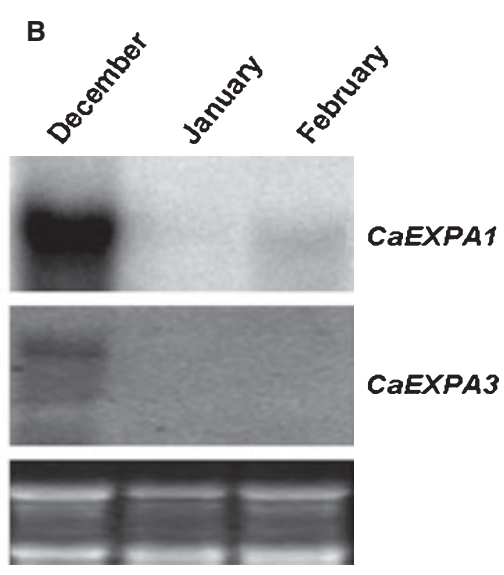

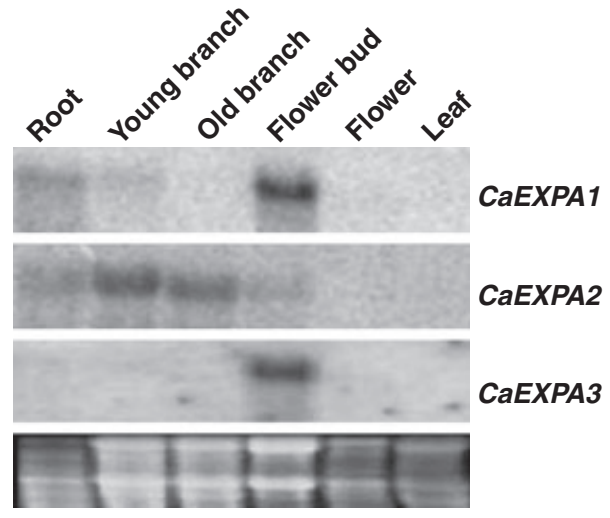

Fig. 7. Organ specific expression of CaEXPA1, CaEXPA2 and CaEXPA3 genes. Total RNA $(15 \mu \mathrm{g})$ was extracted from roots, young branches, old branches, flower buds, flowers and leaves of C. arabica cv. IAPAR 59. Ethidium bromide-stained gel prior to blotting is shown below the blot as a loading control.

absence of this subgroup in the coffee database. Additional information on Coffea sequence data might reveal more expansins, including some from the $\beta$ family.

Three $\alpha$-expansin cDNAs, CaEXPA1, CaEXP2 and CaEX$P A 3$, were cloned for further molecular characterisation. $\mathrm{CaE}$ $X P 1$ and CaEXP3 showed higher homology than the CaEXP2 isoform. The first two cDNAs were grouped into the same clade of the phylogenetic tree and shared a very similar transcription pattern (Figs 4 and 5), as discussed below. Asha et al. (2007) identified five banana expansins (MaEXPA1MaEXPA5); of these MaEXPA3, MaEXPA4 and MaEXPA5 showed high sequence homology and clustered together in the phylogenetic tree. However, despite the high homology, they differed in their expression patterns.

A dot-blot analysis was first used to test the specificity of each probe and no cross-hybridisation was observed (data not shown). Southern blot analysis of these three Arabica coffee $\alpha$-expansins revealed unique patterns for each probe (Fig. 3). The restriction signals of CaEXPA1, CaEXPA2 and CaEXPA3 suggest that these genes are encoded as two copies in C. arabica. Since C. arabica is an allotetraploid, each parental species (C. canephora and C. eugenioides) can contribute one homeologous gene. The Southern hybridisation signals for CaEXPA1 and CaEXPA2 were similar in $\mathrm{cv}$. IAPAR-59 and cv. IAPAR-59 Graúdo. However, the observed difference in the band pattern of CaEXPA3 suggests that the genomic structure of this isoform differs in these two genotypes (Fig. 3).

Northern blot analyses were initially used to observe transcriptional expression of each $\alpha$-expansin isoform in different non-fruit coffee tissues (Fig. 7). Other than fruits, CaEXPA1 and CaEXPA3 isoforms showed high mRNA accumulation in flower buds. On the other hand, CaEXPA2 showed mRNA expression in roots, young and old branches, and at a comparatively low level in flower buds (Fig. 7). The presence of these transcripts in flower buds is probably due to the intense cell expansion and elongation that occurs in this tissue. In Kyoho grape, Ishimaru et al. (2006) reported the identification and characterisation of three $\alpha$-expansin cDNAs. From these, VlEXP1 and VlEXP2 were expressed at high levels in leaves, tendrils, roots, flowers and seeds, while VlEXP3 was fruit-specific. Differential transcriptional activity of EXP isoforms in plant organs has also been reported in Arabidopsis (Bibikova et al. 1998; Cho \& Cosgrove 2002), maize (Zhang \& Hasenstein 2000), soybean (Lee et al. 2003) and Rumex palustris (Colmer et al. 2004).

During development and ripening, fruits undergo various changes in colour, texture, aroma and taste. Expansins are known to participate in these processes and are also believed to prepare the cell wall for subsequent degradation by cell wall hydrolases during ripening, particularly in climacteric fruits (Trivedi \& Nath 2004). To characterise expression patterns of the three $\alpha$-expansin genes at various stages of coffee fruit development, RNA gel blot analysis was also performed using mRNA extracted from whole coffee fruit at different stages of development. CaEXPA1 and CaEXPA3 transcription patterns were similar in the whole fruit of C. arabica (Fig. 4). Expression of both isoforms was observed in the early stages of fruit development and in the later stages of ripening. It is tempting to speculate that the prolonged transcription of CaEXPA1 and CaEXP3 until 90 DAF in IAPAR-59 Graúdo (Fig. 5), a genotype characterised by larger fruits than IAPAR-59, is involved in modulation of fruit size. At this stage of development (30-90 DAF), the perisperm undergoes intense cell division, elongation and cell wall softening (De Castro \& Marraccini 2006). 
Differential expansin expression during fruit development and ripening has also been reported in several different fruits. For example, Hiwasa et al. (2003) isolated seven expansin cDNAs from pear (PcExp1-PcExp7) and characterised their expression patterns at various fruit development stages. The pear expansins were separated in three categories according to their unique expression profiles: (i) up-regulated at ripening, (ii) expressed but with no significant change during ripening and (iii) undetectable in ripening fruit. In Kyoho grape berries Ishimaru et al. (2006) observed essentially two expression patterns: increased expression with berry development up to the half-coloured stage and decreased until the mature stage (Vlexp1 and Vlexp3), and increased expression before véraison, peaking at véraison and then remaining at high levels up to the maturation stage (Vlexp2). The expression pattern observed for CaEXPA1 and CaEXPA3 in the whole fruit was very similar to that observed in grapes for Vlexp1 and Vlexp3. CaEXPA1 and CaEXPA3 had increased expression during the rapid fruit expansion stage and during pericarp colour change. In contrast, CaEXPA2 increased its expression after pericarp colour change in the final steps of fruit maturation.

In order to assess the contribution of individual tissues to transcription levels of each $\alpha$-expansin isoform, C. arabica fruits were separated into endosperm, perisperm and pericarp. CaEXPA1 and CaEXPA3 transcription patterns detected in the pericarp were similar to those observed in whole fruit. After rapid fruit expansion (90 DAF), transcript levels of these two isoforms were down-regulated, and started to increase again at the ripening stages, a phase in which intense cell wall elongation and disassembly occurs in the pericarp. The simultaneous expression of both CaEXPA1 and CaEXP3 may be important for cell wall loosening during coffee fruit development and for ripening, as these two $\alpha$-expansins may act synergistically during pericarp softening in the final stages of maturation. Another possibility is that these two $\alpha$-expansins act on different components of the cell wall (Im et al. 2000).

In IAPAR-59 Graúdo, the transition time among green and yellow-green fruits occurs early (at $180 \mathrm{DAF}$ ), the phase when we observed high mRNA accumulation for CaEXPA1 and CaEXP3; however the transition time in IAPAR-59 occurs between 180 DAF and 210 DAF. The highest level of both mRNA forms in fruits harvested at 180 DAF for IAPAR-59 Graúdo (Fig. 5) indicates that processes related to fruit ripening might have occurred earlier in the pericarp of this cultivar. Differential expression of expansins in apple pericarp during fruit growth was also observed by Kasai et al. (2008). The expression pattern of isoform (MdEXPA3) was related to the growth rate of apple fruit, suggesting that this may control pericarp enlargement by regulating cell expansion. In our study, despite the difference in the time course, the transcription pattern of the three $\alpha$-expansins seems to be related to the same process of pericarp expansion in both IAPAR-59 and IAPAR-59 Graúdo.

About 90 days after flowering, the perisperm undergoes a process of rapid cell wall division and expansion, which in turn determines the physical limit of the space that will be occupied by endosperm. The highest transcription of $\mathrm{CaEX}$ PA1 in cv. IAPAR-59 Graúdo at 90 DAF, compared to the small grain in cv. IAPAR-59 (Fig. 5), suggests possible involvement of CaEXPA1 in the modulation of final fruit size ib cv. IAPAR-59 Graúdo. Although CaEXPA3 transcription in the perisperm was low, we cannot discard a supplemental role for this isoform in perisperm formation. Further research using RTq-PCR will help to clarify the roles of CaEXP1 and CaEXP3 in perisperm development. As the Southern blot analyses using a CaEXPA3-specific probe showed distinct hybridising bands in the two cultivars, it will be interesting to assess if the size polymorphism observed in one of the bands can be related to the differences in grain size. Further analyses of the genomic organisation of all three $\alpha$-expansins in these two cultivars are underway to provide additional information for understanding the role of these genes in coffee fruit development.

In climacteric fruits, such as coffee, ethylene is considered to be the trigger for fruit ripening events (Pereira et al. 2005). Due to the role of expansins in fruit ripening, various research groups have associated the modulation of expansin expression with ethylene (Rose et al. 1997; Hayama et al. 2006; Asha et al. 2007; Jackson 2008). CaEXPA2 hybridisation with mRNA from the whole coffee fruit and the pericarp indicates the specific action of this isoform only in the final steps of fruit ripening in both IAPAR-59 and IAPAR-59 Graúdo, when there is increased production of ethylene (Pereira et al. 2005). In addition, specific expression in the pericarp and absence of transcripts in the perisperm and endosperm, suggests that CaEXPA2 expression could be modulated by ethylene. This coffee $\alpha$-expansin isoform shows a similar mRNA expression pattern to the fruit-specific and ripening-related expansins MaEXPA1 (Trivedi \& Nath 2004) and MaEXPA2 (Asha et al. 2007) in banana. Both of these genes are expressed abundantly only in mature fruit during ethylene-induced ripening and are repressed in fruit treated with 1-MCP (1-methylcyclopropene, an ethylene perception inhibitor).

Here, we present the first study on expression of $\alpha$-expansins in different tissues during coffee fruit ontogeny. The

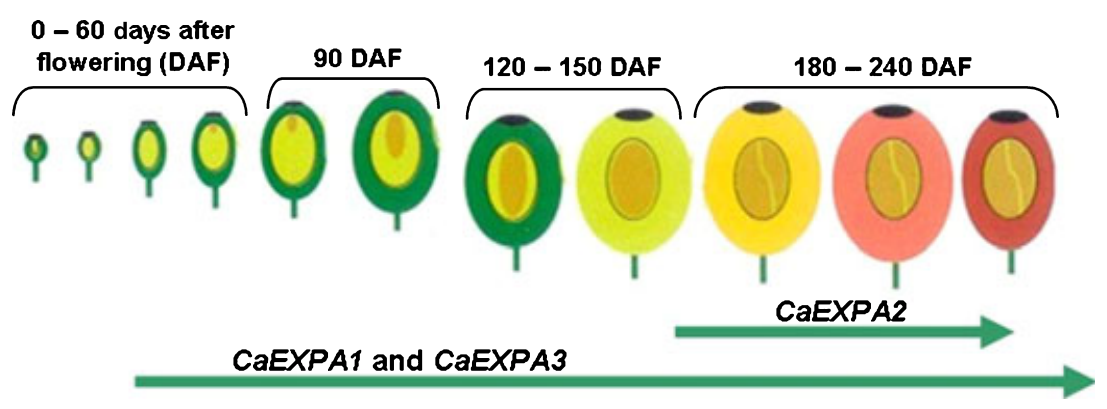

Fig. 8. Hypothetical transcription pattern of CaEXPA1, CaEXPA2 and CaEXPA3 $\alpha$-expansin isoforms during coffee fruit development and ripening. Illustration adapted from De Castro \& Marraccini (2006). 
three $\alpha$-expansin isoforms examined showed differences in spatial and temporal transcription patterns (Fig. 8). As expansins might operate on different components of the cell wall, substrate specificity might explain the different expression of $\alpha$-expansins in coffee fruit tissues described here. While CaEXPA1 and CaEXP3 expression was mainly at stages when the coffee grain size is defined, CaEXPA2 specificity to the pericarp indicates a role for this isoform during the ripening process (Fig. 8). Even taking into account that $\alpha$-expansins are encoded by a large multigene family with functional redundancy, the three isoforms presented here are attractive candidates for manipulating coffee fruit development and ripening.

\section{ACKNOWLEDGEMENTS}

This project was supported by the Brazilian Consortium for Coffee Research and Development (CBP\&D-Café). L.F.P. Pereira and L.G.E. Vieira received a research fellowship from CNPq. I.G.F. Budzinski and T.B. Santos received a student fellowship from CBP\&D-Café.

\section{SUPPORTING INFORMATION}

Additional Supporting Information may be found in the online version of this article:

Figure S1. Differences in fruit size between C. arabica cv. IAPAR-59 and C. arabica cv. IAPAR-59 Graúdo. Black bar $=1 \mathrm{~cm}$.

Please note: Wiley-Blackwell are not responsible for the content or functionality of any supporting materials supplied by the authors. Any queries (other than missing material) should be directed to the corresponding author for the article.

\section{REFERENCES}

Altschul S.F., Gish W., Miller W., Meyers E.W., Lipman D.J. (1990) Basic local alignment search tool. Journal of Molecular Biology, 215, 403-410.

Asha V.A.S., Aniruddha P.S., Pravendra N. (2007) Multiple forms of $\alpha$-expansin genes are expressed during banana fruit ripening and development. Postharvest Biology and Technology, 45, 184192.

Bibikova T.N., Jacob T., Dahse I., Gilroy S. (1998) Localized changes in apoplastic and cytoplasmic $\mathrm{pH}$ are associated with root hair development in Arabidopsis thaliana. Development, 125, 2925-2934.

Brummell D.A., Harpster M.H., Civello P.M., Palys J.M., Bennett A.B., Dunsmuir P. (1999) Modification of expansin protein abundance in tomato fruit alters softening and cell wall polymer metabolism during ripening. The Plant Cell, 125, 2203-2216.

Cho H.T., Cosgrove D.J. (2002) Regulation of root hair initiation and expansin gene expression in Arabidopsis. The Plant Cell, 14, 3237-3253.

Choi D., Cho H.T., Lee Y. (2006) Expansins: expanding importance in plant growth and development. Physiologia Plantarum, 126, 511-518.

Civello P.M., Powell A.L.T., Sabehat A., Bennett A.B. (1999) An expansin gene expressed in ripening strawberry fruit. Plant Physiology, 121, 1273-1279.
Colmer T.D., Peeters A.J., Wagemaker C.A., Vriezen W.H., Ammerlaan A., Voesenek L.A. (2004) Expression of alpha-expansin genes during root acclimations to $\mathrm{O}_{2}$ deficiency in Rumex palustris. Plant Molecular Biology, 56, 423-437.

Cosgrove D.J. (2000) Loosening of plant cell walls by expansins. Nature, 407, 321-326.

Cosgrove D.J. (2005) Growth of the plant cell wall. Nature Reviews, 6, 850-861.

Cosgrove D.J., Bedinger P., Durachko D.M. (1997) Group I allergens of grass pollen as cell wall-loosening agents. Proceedings of the National Academy of Sciences USA, 94, 6559-6564.

De Castro R.D., Marraccini P. (2006) Cytology, biochemistry and molecular changes during coffee fruit development. Brazilian Journal of Plant Physiology, 18, 175-199.

Dotto M.C., Martínez G.A., Civello P.M. (2006) Expression of expansin genes in strawberry varieties with contrasting fruit firmness. Plant Physiology and Biochemistry, 44, 301-307.

Doyle J.J., Doyle J.L. (1987) A rapid DNA isolation procedure for small quantities of fresh leaf tissue. Phytochemistry Bulletin, 19, $11-15$.

Eira M.T.S., Da Silva E.A.A., De Castro R.D., Dussert S., Walters C.J., Bewley D., Hilhorst H.W.M. (2006) Coffee seed physiology. Brazilian Journal of Plant Physiology, 181, 149-163.

Fleming A.J., McQueen-Mason S.J., Mandel T., Kuhlemeier C. (1997) Induction of leaf primordia by the cell wall protein expansin. Science, 276, 1415-1418.

Geromel C., Ferreira L.P., Guerreiro S.M.C., Cavalari A.A., Pot D., Pereira L.F.P., Leroy T., Vieira L.G.E., Mazzafera P., Marraccini P. (2006) Biochemical and genomic analysis of sucrose metabolism during coffee (Coffea arabica) fruit development. Journal of Experimental Botany, 55, 2-16.

Geromel C., Ferreira L.P., Davrieux F., Guyot B., Ribeyre F., Scholz M.B.S., Pereira L.F.P., Vaast P., Pot D., Leroy T., Filho A.A., Vieira L.G.E., Mazzafera P., Marraccini P. (2008) Effects of shade on the development and sugar metabolism of coffee (Coffea arabica L.) fruits. Plant Physiology and Biochemistry, 46, 569-579.

Hayama H., Shimada T., Fujii H., Ito A., Kashimura Y. (2006) Ethylene regulation of fruit softening and softening-related genes in peach. Journal of Experimental Botany, 57, 4071-4077.

Hiwasa K., Rose J.K.C., Nakano R., Inaba A., Kubo Y. (2003) Differential expression of seven $\alpha$-expansin genes during growth and ripening of pear fruit. Physiologia Plantarum, 117, 564-572.

Im K.H., Cosgrove D.J., Jones A.M. (2000) Subcellular localization of expansin mRNA in xylem cells. Plant Physiology, 123, 463-470.

Ishimaru M., Smith D.L., Gross K.C., Kobayashi S. (2006) Expression of three expansin genes during development and maturation of Kyoho grape berries. Journal of Plant Physiology, 164, $1675-1682$.

Jackson M.B. (2008) Ethylene-promoted elongation: an adaptation to submergence stress. Annals of Botany, 101, 229-248.

Kasai S., Hayama H., Kashimura Y., Kudo S., Osanai Y. (2008) Relationship between fruit cracking and expression of the expansin gene MdEXPA3 in 'Fuji' apples (Malus domestica Borkh.). Scientia Horticulturae, 116, 194-198.

Lee D.K., Ahn J.H., Song S.K., Choi Y.D., Lee J.S. (2003) Expression of an expansin gene is correlated with root elongation in soybean. Plant Physiology, 131, 985-997. 
Li Y., Jones L., McQueen-Mason S. (2003) Expansins and cell growth. Current Opinion in Plant Biology, 6, 603-610.

Lin Z., Ni Z., Zhang Y., Yao Y., Wu H., Sun Q. (2005) Isolation and characterization of 18 genes encoding $\alpha$ - and $\beta$-expansins in wheat (Triticum aestivum L.). Molecular Genetics and Genomics, 274, 548-556.

McQueen-Mason S., Cosgrove D.J. (1995) Expansin mode of action on cell walls. Plant Physiology, 107, 87-100.

McQueen-Mason S., Durachko D.M., Cosgrove D.J. (1992) Two endogenous proteins that induce cell wall extension in plants. Plant Cell, 4, 1425-1433.

Obenland D.M., Crisosto C.H., Rose J.K.C. (2003) Expansin protein levels decline with the development of mealiness in peaches. Postharvest Biology and Technology, 29, 11-18.

Omondi W.O., Nakano R., Kubo Y., Inaba A. (2004) Coordinated expression patterns of genes encoding cell wall modifying enzymes during ripening in distinct anatomical tissue regions of the fig (Ficus carica L.) fruit. Postharvest Biology and Technology, 32, 253-261.

Pereira L.F.P., Galvão R.M., Kobayashi A.K., Cação S.M.B., Vieira L.G.E. (2005) Ethylene production and acc oxidase gene expression during fruit ripening of Coffea arabica L. Brazilian Journal of Plant Physiology, 17, 283-289.

Powell A.L.T., Kalamaki M.S., Kurien P.A., Gurrieri S., Bennet A.B. (2003) Simultaneous transgenic suppression of LePG and LeExp1 influences fruit texture and juice viscosity in a fresh market tomato variety. Journal of Agricultural and Food Chemistry, 51, 7450-7455.

Rose J.C., Lee H.H., Bennett A.B. (1997) Expression of a divergent expansin gene is fruit-specific and ripening-regulated. Proceedings of the National Academy of Sciences USA, 94, 5955-5960.

Salmona J., Dussert S., Descroix F., Kochko A., Bertrand B., Joet T. (2008) Deciphering transcriptional networks that govern Coffea arabica seed development using combined cDNA array and real-time RT-PCR approaches. Plant Molecular Biology, 66, $105-124$.

Sambrook J., Fritsch E.F., Maniatis T. (1989) Molecular cloning: a laboratory manual. 2nd edition. Cold Spring Harbor Laboratory, Cold Spring Harbor, NY, USA.
Sampedro J., Cosgrove D.J. (2005) The expansin superfamily. Genome Biology, 6, 242.1-241.11.

Sampedro J., Lee Y., Carey R.E., de Pamphilis C., Cosgrove D.J. (2005) Use of genomic history to improve phylogeny and understanding of births and deaths in a gene family. The Plant Journal, 44, 409-419.

Sane V.A., Chourasia A., Nath P. (2005) Softening in mango (Mangifera indica var Dashehari) is correlated with the expression of an early ethylene responsive, ripening related expansin gene, MiExpA1. Postharvest Biology and Technology, 38, 223-230.

Trivedi K.P., Nath P. (2004) MaExp1, an ethylene-induced expansin from ripening banana fruit. Plant Science, 167, 13511358.

Vieira L.G.E., Andrade A.C., Colombo C.A., Moraes A.H.A., Metha A., Oliveira A.C., Labate C.A., Marino C.L., Monteiro-Vitorello C.B., Monte D.C., Giglioti E., Kimura E.T., Romano E., Vitorello C.B.M., Kuramae E.E., Lemos E.G.M., Almeida E.R.P., Jorge E.C., Albuquerque E.V.S., Silva F.R., Vinecky F., Sawazaki H.E., Dorry H.A., Carrer H., Abreu I.N., Batista J.A.N., Teixeira J.B., Kitajima J.P., Xavier K.G., Lima L.M., Camargo L.E.A., Pereira L.F.P., Coutinho Ll., Lemos M.V.F., Romano M.R., Costa M.M.C., Machado M.A., Sá M.F.G., Goldman M.H.S., Ferro M.I.T., Tinoco M.L.P., Oliveira M.C., Sluys M.V., Shimizu M.M., Maluf M.P., Eira M.T.S., Guerreiro Filho O., Arruda P., Mazzafera P., Mariani P.D.S.C., Oliveira R.L.B.C., Harakava R., Balbao S.F., Tsai S.M., DiMauro S.M.Z., Santos S.N., Siqueira W.J., Costa G.G.L., Formighieri E.F., Carazzolle M.F., Pereira G.A.G. (2006) Brazilian coffee genome project: an EST-based genomic resource. Brazilian Journal of Plant Physiology, 18, 95108.

Yong L., Liu D., Zhang H., Gao H., Guo H., Wang D., Zhang X., Zhang A. (2007) The $\alpha$ - and $\beta$-expansin and xyloglucan endotransglucosylase/hydrolase gene families of wheat: molecular cloning, gene expression, and EST data mining. Genomics, 90, 516-529.

Zhang N., Hasenstein K.H. (2000) Distribution of expansins in graviresponding maize roots. Plant and Cell Physiology, 41, 1305-1312. 